\title{
Could Propafenone hydrochloride Cause Visual Hallucination?
}

\author{
Tanzer Korkmaz', Nihat Pekel2, Süveyda Yeşilaras', Deniz Oray', Cem Ertan' \\ 'Department of Emergency, Izmir University Faculty of Medicine, Izmir, Turkey \\ ${ }^{2}$ Department of Cardiology, İmir University Faculty of Medicine, İmir, Turkey
}

\begin{abstract}
Introduction: There may be some cardiac and non-cardiac side effects of propafenone hydrochloride, which is a class IC antiarrhythmic agent used for medical cardioversion in atrial fibrillation and atrial flutter.

Case Report: Propafenone hydrochloride $(600 \mathrm{mg}$ ) was orally administered to a 74-year-old patient with tachycardia due to new-onset atrial fibrillation with rapid ventricular response. After 30 min, sinus bradycardia in response to atropine, swelling and numbness in the tongue, slurred speech, blurred vision, diplopia, spasm and contradiction at the right arm and leg, drowsiness, and visual hallucinations lasting for $24 \mathrm{~h}$ developed. The patient recovered without any sequel and was discharged from the coronary intensive care unit.

Conclusion: Although propafenone hydrochloride is known to be safe at therapeutic doses, various possible multiple side effects should be considered.
\end{abstract}

Keywords: Propafenone $\mathrm{HCl}$, side effect, hallucinations, emergency service

Received:24.06.2015 Accepted: 17.08.2015

\section{Introduction}

Propafenone hydrochloride $(\mathrm{HCl})$ is a class IC antiarrhythmic agent used for medical cardioversion in atrial fibrillation, atrial flutter, and paroxysmal supraventricular tachycardia (PSVT) (1). It slows down nerve conduction through the direct stabilization of the myocardial membrane via Na channel blockage (which increases the atrioventricular nodal refractory period). In addition to its action of directly slowing innervation of the heart tissue, it also has some calcium-channel and beta-receptor blocking effects. These properties make propafenone $\mathrm{HCl}$ an effective converting agent for up to $40 \%-70 \%$ of patients with atrial flutter and fibrillation (2). It directly works on the heart tissue and slows the nerve impulses to keep the heart rhythm normal. Compared with other class IC agents, propafenone $\mathrm{HCl}$ has a lower observed prodysrhythmic rate in therapeutic doses. In a review, it was stated that a single $600 \mathrm{mg}$ dose of propafenone $\mathrm{HCl}$ is considered to be effective and safe to convert AF rhythm to sinus rhythm (3). The most common side effects include conduction disturbances on an electrocardiogram (ECG), blurred vision, dysgeusia, and dizziness. Other side effects mostly include non-cardiac effects such as nausea/ vomiting, dry mouth, constipation, dyspepsia, fatigue, tinnitus, palpitations, abdominal pain, fever, vision abnormalities, and unusual dreams (4). Here, we report this case because of the coexistence of both frequent cardiovascular and rare noncardiac side effects after the administration of a single dose of propafenone $\mathrm{HCl}$.

\section{Case Report}

A 74-year-old female patient with a history of hypertension presented to the emergency department with a complaint of palpitation. She denied any chest pain or light-headedness and had no history of prior palpitations, diabetes, and angina or myocardial infarction. She was on $100 \mathrm{mg}$ aspirin, $150 \mathrm{mg}$ dabigatran eteksilat, $50 \mathrm{mg}$ metoprolol, and 160/12.5 mg hidroklorotiazid valsartan. On examination, she was alert, oriented, and cooperative; had a Glasgow Coma Scale score of 15; and an oxygen saturation of $99 \%$. Her pulse was irregular at 158 beats/min. Her blood pressure was 153/95 mmHg, her respiratory rate was 20 breaths/min, and she was afebrile. Her lungs were clear to auscultation, and she had no murmurs or extra heart sounds. After the patient was monitor-

This study was presented at $4^{\text {th }}$ Mediterranean Emergency Medicine Congress (MEMC) - Global Research on Acute Conditions Team (GREAT) 5-9 September 2015, Rome, Italy.

Address for Correspondence:

Tanzer Korkmaz, Department of Emergency, Izmir University Faculty of Medicine, Izmir, Turkey

E-mail: tanzerkorkmaz@gmail.com

oCopyright 2016 by Emergency Physicians Association of Turkey - Available online at www.jemcr.org 


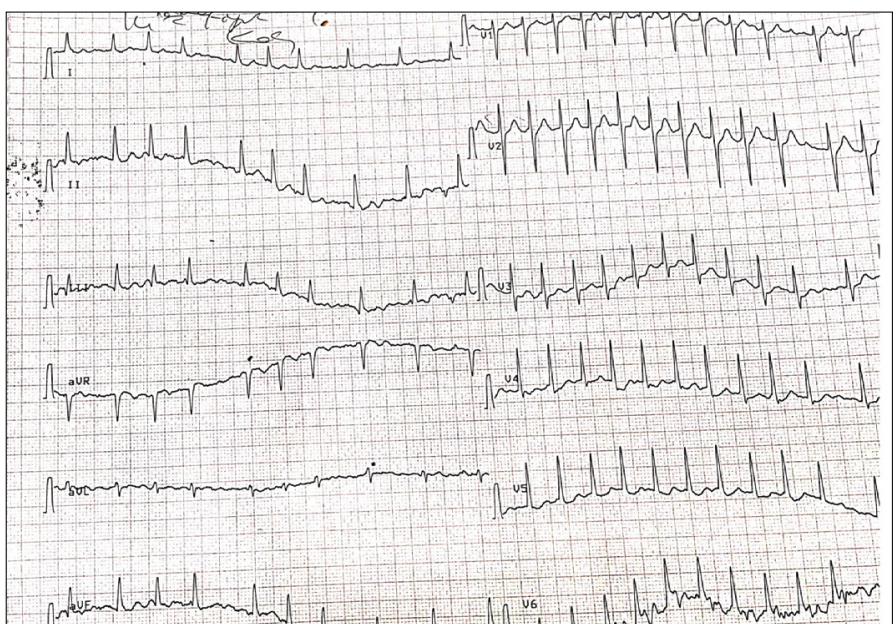

Figure 1. ECG findings revealed AF with rapid ventricular response

ized, an ECG was taken, and she was diagnosed to have AF with a rapid ventricular response (Figure 1). Diltiazem (25 mg) was intravenously administered for rate control. Pulse rate decreased to 100 beats/min, but it continued irregularly, and her complaints of palpitation continued. Her blood pressure dropped to $70 / 40 \mathrm{mmHg}$. Cardiology consultation was requested for new-onset AF. Peroral propafenone $\mathrm{HCl}$ (600 mg) was given to the patient for rhythm control, and possible cardioversion was conducted following echocardiography examination. Conversion to sinus rhythm was achieved an hour after the administration of propafenone $\mathrm{HCl}$ (Figure 2). After 30 min, short-term sinus pause ( $<10 \mathrm{~s})$ and two symptomatic sinus bradycardia periods with 30-min intervals (pulse rate: 30 beats/min) occurred. The level of consciousness and general condition of the patient improved, and pulse rate reached to a level of 70-80 beats/min following the consecutive intravenous administration of $1 \mathrm{mg}$ atropine twice in sequence. Troponin I value was within the normal range. After $2 \mathrm{~h}$, swelling and numbness in the tongue, slurred speech, blurred vision, and diplopia developed. The patient stated that there were spasms and contractions, particularly in the right arm and leg. In simultaneous measurements, blood glucose level was $116 \mathrm{mg} / \mathrm{dL}$, sinus rhythm was detected on ECG, and no neurologic deficit was determined. No electrolyte disturbances were determined in the laboratory workup. Meanwhile, drowsiness increased and visual hallucinations and hand movements as if she was pointing out to something emerged. When the patient was questioned about the gestures, she explained that a girl who she has supposedly met previously but has no recollection of her name came up and then another man and woman brought flowers and that she was trying to reach the flowers. Because of the continuation of visual hallucinations, diffusion magnetic resonance imaging was performed, and it revealed no pathological findings. All findings were considered to be side effects related to propafenone $\mathrm{HCl}$, and cardiology consultation was repeated and then the patient was hospitalized to the intensive care unit for follow-up. All side effects disappeared after $18 \mathrm{~h}$, and the patient was discharged after 2 days.

\section{Discussion}

Rhythm control is recommended for the patients who are $\leq 65$ years old, those with new-onset AF, those without heart failure and who have not experienced heart failure under previous antiarrhythmic drug use, and in patients who demand rhythm control (5).

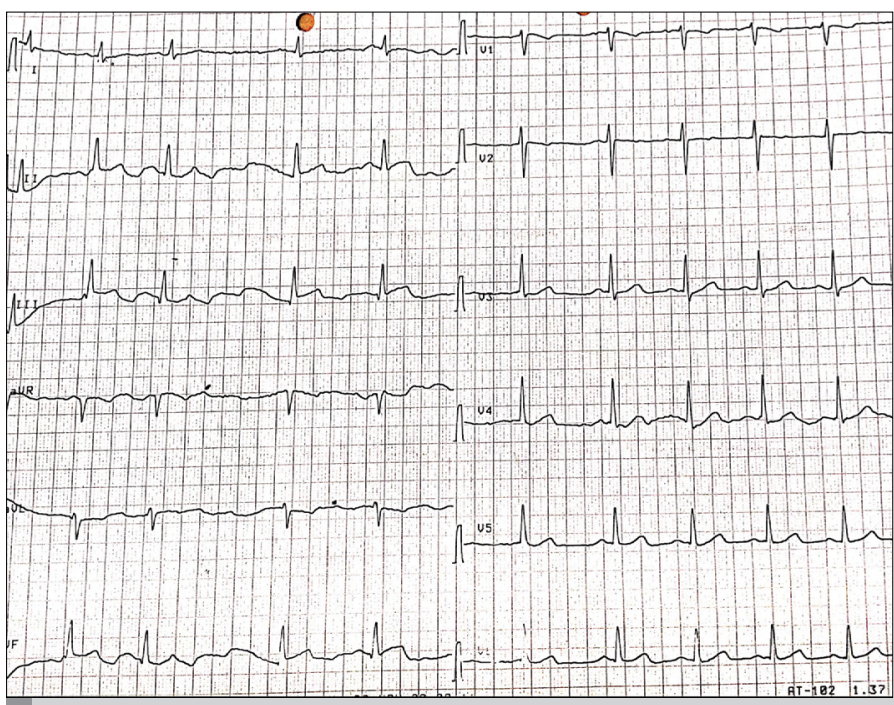

Figure 2. Conversion to sinus rhythm was achieved with propafenone $\mathrm{HCl}$

Dronedarone, flecainide, propafenone, or sotalol may be used in patients without structural defects to control rhythm and to maintain sinus rhythm. Only amiodarone is recommended in patients with an ejection fraction lower than 35. Left ventricular dysfunction and deterioration of congestive heart failure may occur because of beta-blocker and dose-dependent negative inotropic effects of propafenone $\mathrm{HCl}$ on the myocardium (5). Because there were no described heart failure or physical examination findings of our patient and she was not under any antiarrhythmic agents and had new-onset $\mathrm{AF}$, propafenone $\mathrm{HCl}$ was preferred for rhythm conversion. Although the side effects of propafenone $\mathrm{HCl}$ are dose dependent, its cardiac toxic effects may cause hypotension, ventricular dysrhythmias, and sudden death in therapeutic doses (6). Koppel et al. (6) reported that class IC agents cause bradyarrhythmias in two-thirds of the patients. Symptomatic sinus bradycardia responding to atropine developed twice in our case. Although propafenone $\mathrm{HCl}$ itself may solely cause bradycardia, this adverse effect may have also emerged as a result of propafenone HCl's interaction with metoprolol, which has been used by the patient for a long period of time (7).

In therapeutic doses, propafenone $\mathrm{HCl}$ may cause non-cardiac and cardiac toxicities. Non-cardiac adverse effects include cholestatic hepatitis, reactive airway disease, agranulocytosis, hemolysis, drug fever, and ataxia (3). Torres et al. (8) reported that a serious dyspnea occurred in a 78-year-old case when the second dose was applied at the first day of treatment; however, this did not occur in our patient.

Central nervous system side effects of propafenone $\mathrm{HCl}$ are generally dose dependent, and the mechanism of this effect is not completely understood. Sleep disturbances, depression, lethargy, hallucination, delirium, and paranoia may occur because of beta-adrenergic receptor blockage. Pfeffer et al. (9) reported that propafenone $\mathrm{HCl}$ may cause organic psychosis in patients who use venlafaxine because of increased venlafaxine serum levels. Because there is no antipsychotic and similar drug history in our case, hallucinations are believed to be related to propafenone use in therapeutic doses. There is no a standard antidote for the overdose 
of propafenone $\mathrm{HCl}$. Brubacher et al. reported that hypertonic sodium bicarbonate treatment was efficiently used for a patient with wide QRS complex tachycardia related to propafenone administration in a therapeutic dose (450 mg) (3). Bayram et al. (10) reported that a patient who had cardiac arrest following the IV administration od propofenone $\mathrm{HCL}$, recovered with high dose IV insulin. No additional medication other than atropine was administered to our case because no life-threatening cardiac effects were present, and sinus bradycardia responded to atropine.

Although the administration of propafenone $\mathrm{HCl}$ in therapeutic doses at an emergency department is considered safe, it should be considered that even a single and first dose may cause one or more side effects.

Ethics Committee Approval: Ethical committee approval was not deemed necessary.

Informed Consent: Written informed consent was obtained from patient who participated in this study.

Peer-review: Externally peer-reviewed.

Author contributions: Concept -T.K.; Design - T.K., S.Y., D.O.; Supervision - T.K., N.P., S.Y., D.O. C.E.; Resource - T.K.; Materials - T.K., S.Y.; Data Collection and/or Processing - T.K., N.P., S.Y., D.O.C.E.; Analysis and/or Interpretation - T.K., N.P.; Literature Search -T.K., N.P., S.Y., D.O.C.E.; Writing - T.K., N.P., S.Y., D.O.C.E.; Critical Reviews - T.K., N.P., S.Y., D.O. C.E.

Conflict of Interest: No conflict of interest was declared by the authors.
Financial Disclosure: The authors declared that this study has received no financial support.

\section{References}

1. Kawase A, Ikeda T, Nakazawa K, Ashihara T, Namba T, Kubota T, et al. Widening of the excitable gap and enlargement of the core of reentry during atrial fibrillation with a pure sodium channel blocker in canine atria. Circulation 2003; 107: 905-10. [CrossRef]

2. Donald M. Yealy and Theodore R. Dysrhythmias. In Marx JA, Hockberger RS, Walls RM, Adams J, eds. Delbridge.Rosen's emergency medicine, concepts and clinical practice. 7th ed. Philadelphia:PA 19103-2899. 2010: 984-1024.

3. Brubacher J, Bicarbonate therapy for unstable propafenone-induced wide complex tachycardia. Pharmacotherapy CJEM 2004; 6: 349-56.

4. http://www.medicinenet.com/propafenone-oral/page2.htm. Available 11.08.2015.

5. Gillis AM, Verma A, Talajic M, Nattel S, Dorian P; CCS Atrial Fibrillation Guidelines Committee. Canadian Cardiovascular Society atrial fibrillation guidelines 2010: rate and rhythm management. Can J of Cardiol 2011; 27: 47-59. [CrossRef]

6. Koppel C, Oberdisse U, Heinemeyer G, Clinical course and out- come in class IC antiarrhythmic overdose. JToxicol Clin Toxi- col 1990; 28: 433-44. [CrossRef]

7. Wagner F, Kalusche D, Trenk D, Jahnchen E, Roskamm H, Drug interaction between propafenone and metoprolol. Br J Clin Pharmacol 1987; 24: 213-220. [CrossRef]

8. Torres D, Parrinello G, Paterna S, Bellanca M, Licata G, Severe, Brochostenosis by Oral Propafenone Immediately After Commencing Treatment. Am J Ther 2011 Jan 18. [CrossRef]

9. Pfeffer F, Grube M, An organic psychosis due to a venlafaxine-propafenone interaction. Int J Psychiatry Med 2001; 31:427-32. [CrossRef]

10. Bayram B, Dedeoğlu E, Hocaoğlu N, Gazi E, Propafenone-induced cardiac arrest: full recovery with insulin, is it possible? Am J Emerg Med 2013; 31: 457. [CrossRef] 